\title{
The Process Architecture of the Insurance Business
}

\author{
Lech Gąsiorkiewicz \\ Faculty of Management, Warsaw University of Technology, Warsaw, Poland
}

Email address:

lech.gasiorkiewicz@pw.edu.pl

\section{To cite this article:}

Lech Gąsiorkiewicz. The Process Architecture of the Insurance Business. Journal of Business and Economic Development. Vol. 4, No. 2, 2019, pp. 44-52. doi: 10.11648/j.jbed.20190402.12

Received: May 14, 2019; Accepted: June 15, 2019; Published: June 26, 2019

\begin{abstract}
The insurance business has for years constituted both a foundation and an important component of economic activity. Its significance in the conditions of the increasingly complicated and dynamically changing circumstances of economic behavior is steadily growing, generating new problems and setting up new challenges. One of these challenges is to meet the growing requirements and expectations of customers. This requires the efficient management of insurance companies, which in turn means the necessity of reaching for modern management ideas, primarily as related to the concept of process management and the tools related to it. In practice, you can meet two concepts, process management and management of processes. Process management is a broader term consistent with the concept of a process approach, because management of processes refers to selected processes and takes place also in organizations based on a functional approach. Process management is management in accordance with process orientation and process approach. The starting point for the implementation of process management as well as management of process is the identification of processes, a description of their structure and mutual relations. The article presents the concept of the process architecture of insurance activity (distinguishing management processes, basic processes and auxiliary processes), description of basic processes structure by management levels (strategic and operational) and presentations of relations between basic processes and other processes carried out in insurance companies.
\end{abstract}

Keywords: Process, Management of Processes, Process Management, Process Architecture of Insurance Activity, Process Structure, Relationships Between Processes

\section{Introduction}

A condition for occupying the appropriate place in the modern economy and for increasing the level of security in the functioning on a competitive market is the introduction of new systemic solutions in the management of organizations. According to M. Trocki, two approaches in management can be distinguished: functional and process-related. The functional approach places at the forefront static aspects and the functional harmonization of activities and emphasizes the realization of the goals of the organization. The process approach distinguishes dynamic aspects and the harmonization of the processes of activities and also accents the need to satisfy an organization's customer needs. These approaches are not alternative to each other but instead complement each other. An increase in interest in the process approach both on the part of academia and in practice results from the growing need of meeting the needs and expectations of customers [1]. In practice one can find two concepts - the management of processes and process management. Process management is a broader term in keeping with the concept of the process approach while the management of processes refers to selected processes and also occurs in organizations that employ a functional approach to management. Process management is management in accordance with the process orientation and the process approach. Research conducted in Polish property insurance companies showed that out of 21 examined firms none of them implemented process management, in 18 companies (i.e. $85.70 \%$ ) the management of selected processes was implemented and 3 firms (i.e. $14.3 \%$ ) plan to implement process management in the next few years [2]. Conducting work, therefore, in the field of process management in these organizations is fully justified.

The implementation of management of process as well as process management is implemented in stages. According to A. Hallerbach, T. Bauer, M. Reichert, process management includes the following stages: process modeling, process selection, implementation and monitoring of processes and process optimization [3] M. Dumas, M. La Rosa, J. Mendling, H. Reijers 
distinguish: process identification, process discovery, process design analysis, process implementation [4]. N. Verma is distinguished by: defining the goal, identifying the process, classifying the process, determining the tools and implementation processes, monitoring the process [5]. The implementation of process management is a more complex undertaking than the management of processes. According to C. Houy, P. Fettke, P. Loos is implemented as part of the following stages of work: development of strategies in the field of process management, definition and modeling of processes, implementation of processes in the organization, implementation of implemented processes, monitoring and controlling the implementation of processes, optimization and improvement process [6]. G. A. Rummler, A.P. Brache believes that the implementation of process management should be implemented as part of the following stages of work: formulation of strategy, description and analysis of the current organization, description and analysis of currently operating processes, preparation of the process map and their measures, designing the organizational structure, preparation of the description of each function in the structure, preparation of job descriptions, designing employee efficiency systems for each position, introduction of management processes [7].

The aim of the article is to seek answers to the following research questions:

(1) how can one present the process architecture of insurance activity?

(2) what is the structure of the basic insurance business processes?

(3) what are the relationships between basic processes and other processes implemented in insurance companies?

The content contained in this publication applies to property insurance companies, and certain fragments of it may also apply to life insurance companies.

\section{The Process Architecture of the Insurance Business}

Processes are usually grouped into two or three groups. Their division into two groups (basic and auxiliary processes) is recommended by professional organizations (e.g. APQC, the American Productivity and Quality Center) and some specialists (e.g. M. Porter). The second solution divides processes into three groups: basic processes (executive, operational), auxiliary processes (support, service) and management processes. This division is recommended by some professional organizations dealing with process management, e.g. EABPM, the European Association of Business Process Management in their BPM standard CBOK Business Process Management Common Body of Knowledge.

Basic processes are processes related to the basic task of insurance companies, which is providing insurance protection. These include the creation and sale of insurance products and the handling of insurance claims. Auxiliary processes are processes supporting the implementation of basic processes. Thanks to this support, basic processes can bring expected results. The 'products' of these processes are usually not visible to external customers, but have a significant impact on the functioning of the insurance company.

Management processes are processes aimed at ensuring the effective planning and functioning of basic and auxiliary processes, their improvement and for insurance company management.

The concept of the process architecture of insurance activity as per the importance of tasks (functions) performed in insurance companies is presented in Figure 1.

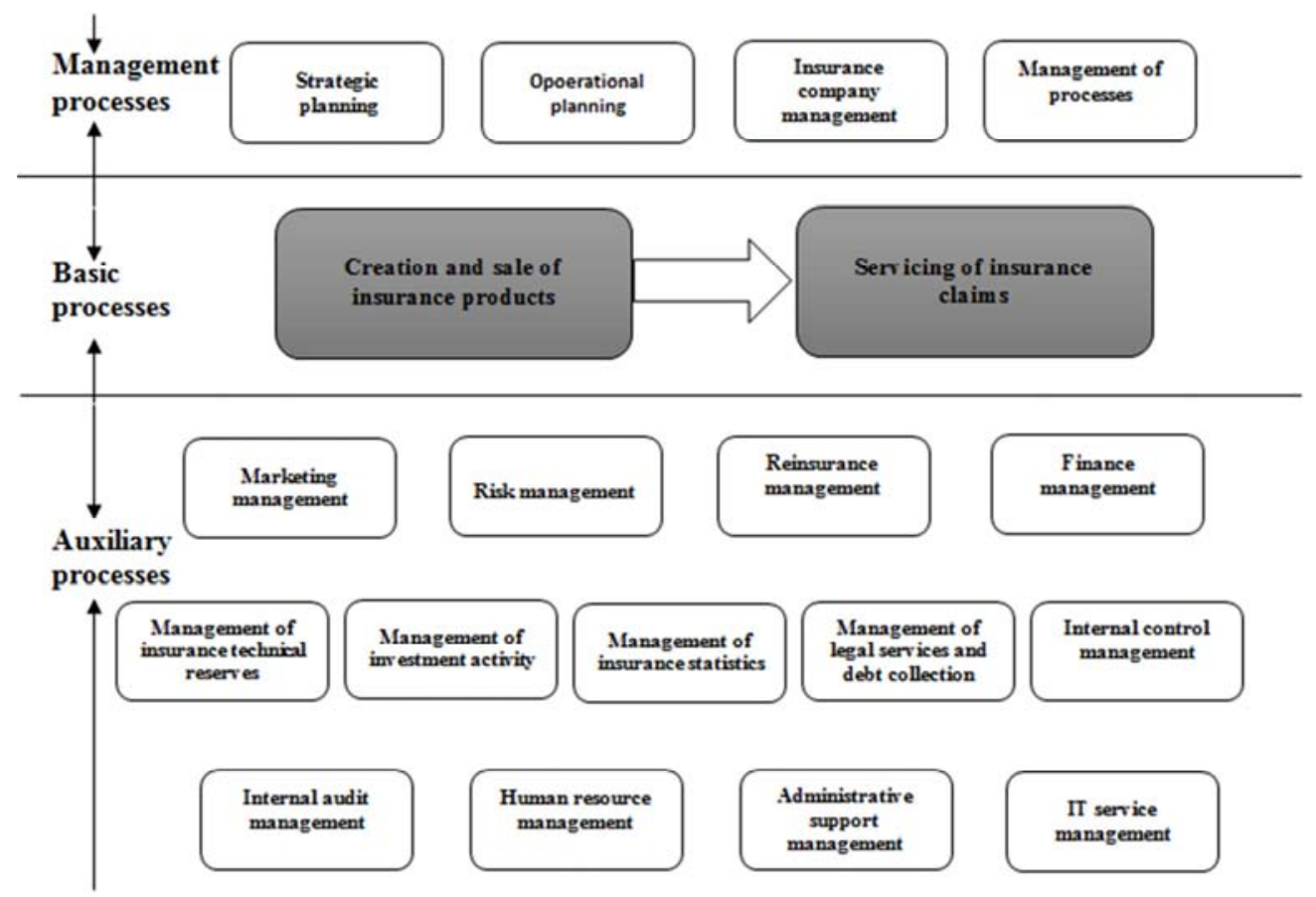

Source: proprietary work on the basis of [8-10]

Figure 1. The concept of the process architecture of insurance activity as per the importance of tasks (functions) performed in insurance companies. 


\section{The Structure of Basic Insurance Business Processes}

The basic processes of insurance activity are: the process of creating and selling insurance products and the process of handling insurance claims. Within these processes, subprocesses implemented on two levels, namely: strategic and operational, can be distinguished.

\subsection{The Structure of the Process of the Creation and Sale of Insurance Products}

The structure of the creation and sales process by management levels is shown in Figure 2.

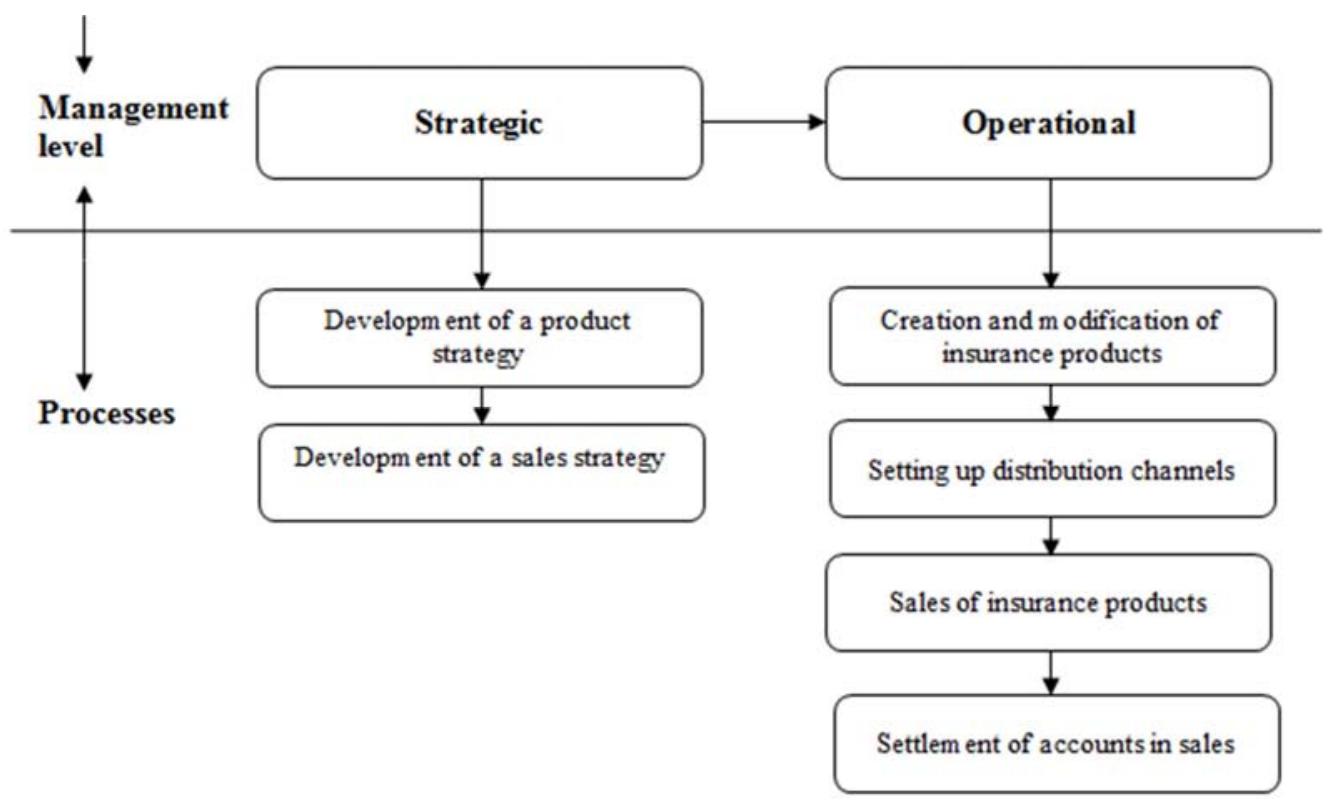

Source: proprietary work

Figure 2. The structure of the process of creating and selling insurance products by management levels.

The strategic level of the process of creating and selling insurance products includes the sub-process of developing a product strategy and the sub-process of developing a sales strategy, which strategies should be correlated with the insurance company's business strategy. The product strategy includes the designation of products that the insurance company will offer to its clients. The selection of products on the one hand results from market demand, and on the other hand from the profitability for the insurance company of the offering of these products. The information contained in the product strategy is the basis for developing new products or modifying existing products.

The operational level of the process of creating and selling insurance products includes the following sub-processes: creating and modifying products, launching distribution channels, selling insurance products and the settling of accounts in sales. These sub-processes consist of specific activities within which the following tasks are carried out:

(1) conducting market needs analysis of insurance products,

(2) creation of new and modification of existing insurance products,

(3) development of general insurance conditions,

(4) assessment of the effectiveness of individual insurance products,

(5) adjustment of insurance tariffs,
(6) launching distribution channels,

(7) providing information materials and insurance forms for insurance agents,

(8) ensuring efficient customer service,

(9) ensuring a high level of customer service,

(10)ensuring the fullest possible fulfilment of customer expectations,

(11)customer service related to the duration of the insurance contract and the undertaking analyses, concerning the process of the insurance contract (check of payment deadlines for premiums, deadlines for resumption of insurance contracts, issuing certificates, etc.),

(12)settlements with insurance agents as regards concluded insurance contracts, collected, premiums and collected strictly registered accountancy documents,

(13)analysis of sales (correctness of insurance contracts concluded, effectiveness of marketing, activities, actuarial information, etc.),

(14)providing fast and reliable information on the results obtained from sales.

The sub-processes and activities of the operational level of the process of creating and selling insurance products are presented in Figure 3. 


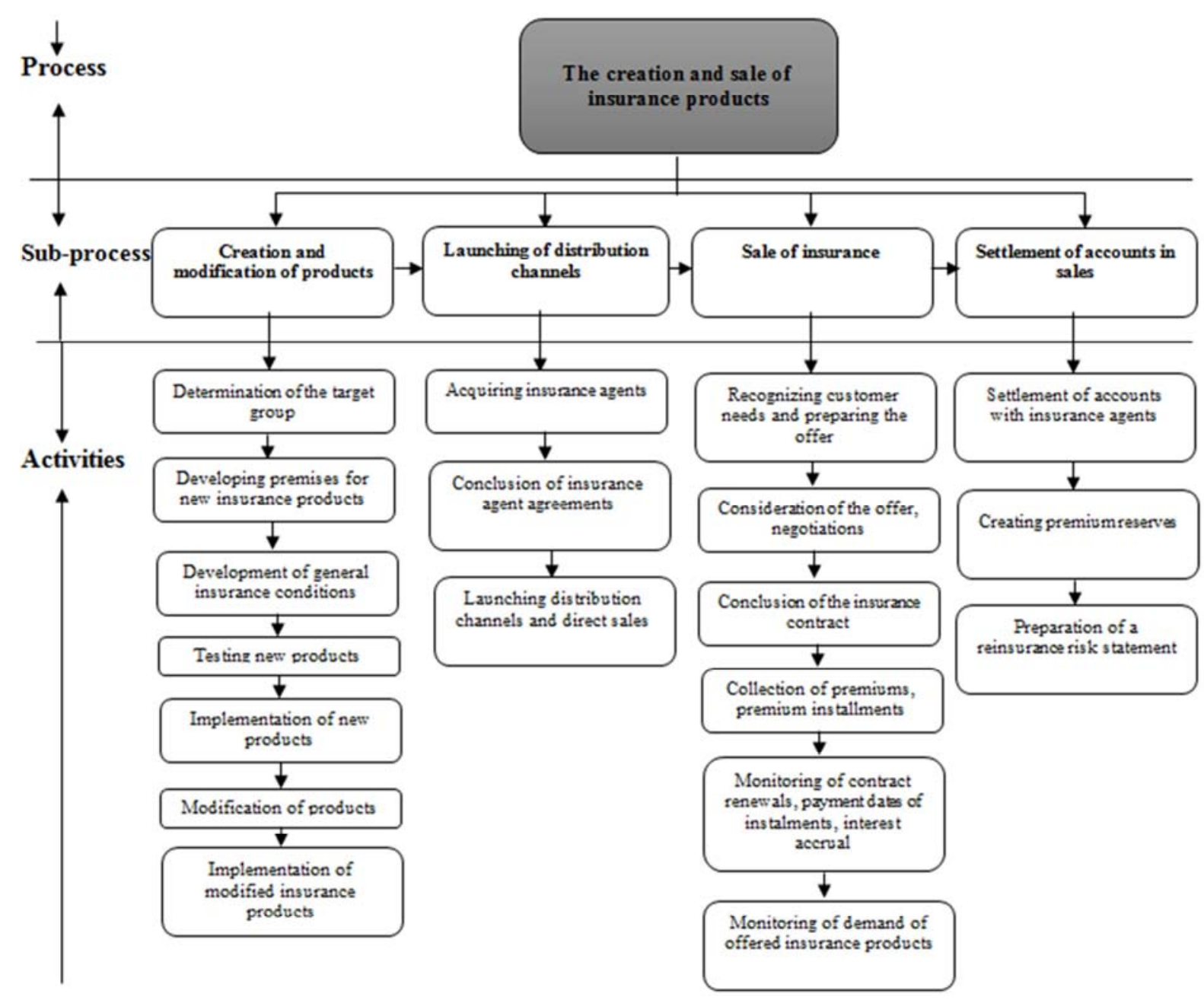

Source: proprietary work

Figure 3. The structure of the operational level of the process of creating and selling insurance products.

\subsection{Structure of the Insurance Claims Handling Process}

The structure of insurance claims handling process by management levels is shown in Figure 4 .

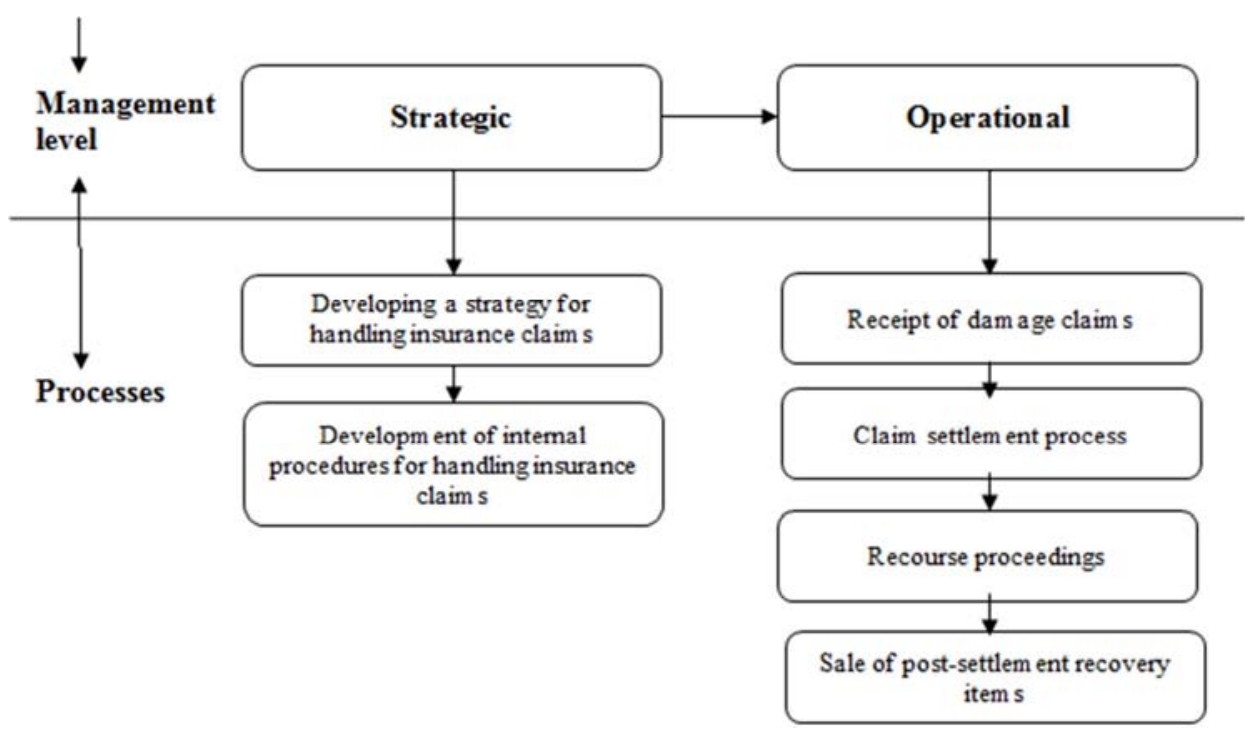

Source: proprietary work

Figure 4. Structure of the process of handling insurance claims by management levels. 
The strategic level includes the sub-process of developing a strategy for handling insurance claims and the sub-process of developing internal procedures for handling insurance claims.

The operational level of the insurance claims handling process includes the following sub-processes: receipt of damage claims, settlement proceedings, settlement proceedings and post-settlement recovery management. These sub-processes (similarly as in the case of the process of creating and selling insurance products) consist of specific activities within which the following tasks are carried out:

(1) ensuring the efficient and easy for clients submission of claims,

(2) analysis of the insurance company's scope of responsibility,
(3) ensuring the adoption of a proper procedure for considering claims,

(4) providing a true estimate of the value of claims,

(5) ensuring an efficient implementation of the insurance company's obligations under the concluded insurance contracts,

(6) preparing motions about recourse based on paid-out settlements, conducting negotiations with debtors with a view to recovering monies owed due to recourse,

(7) selling post-settlement recovery items, and

(8) ensuring the efficient consideration of customer claims related to claim settlements.

Sub-processes and operations at the operational level of the insurance claims handling process are presented in Figure 5.

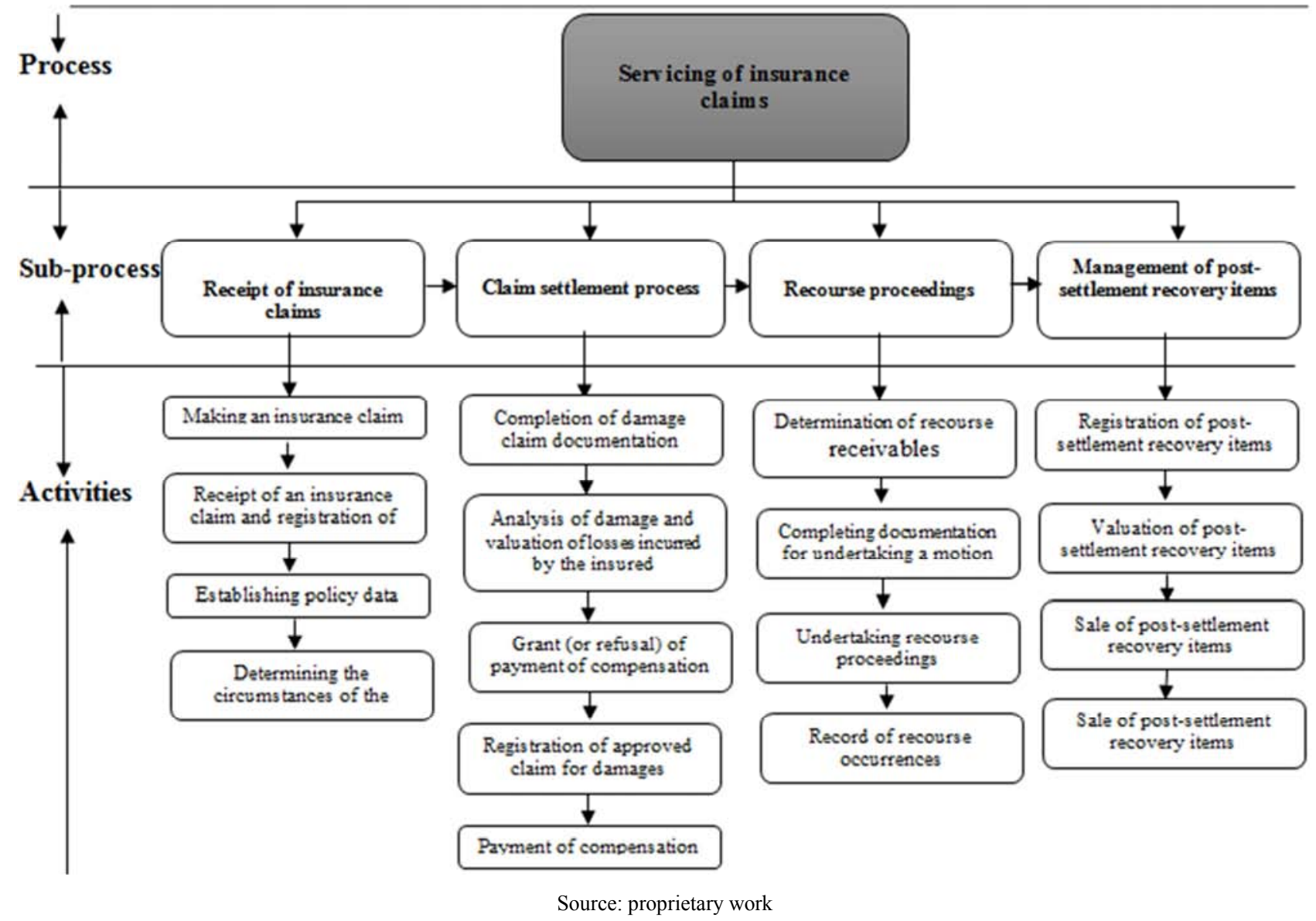

Figure 5. Structure of the operational level of the insurance claims handling proce.

\section{Relations Between Basic Processes and Other Processes Implemented in Insurance Companies}

\subsection{Relations Between the Creation and Sale of Insurance Products and Other Processes Carried Out in Insurance Companies}

The relationship between the creation and sale of insurance products and other processes carried out in insurance companies is presented in Figure 6.

The process of creating and selling insurance products is supported by information (dotted lines in Figure 6) from:

(1) the strategic planning process for strategic plans for the creation and sale of insurance products,

(2) the operational planning process related to operational plans for the creation of and sale of insurance products,

(3) the process management process in the field of modelling, research and evaluation of the process of 
the creation and sale of insurance products,

(4) the marketing management process about the results of marketing activities,

(5) the risk management process in the area of the identification, estimation and monitoring of risks related to the creation and sale of insurance products,

(6) the process of managing of servicing of legal matters and debt collection in the area of legal services for creation of insurance products, their sale and related debt collection activities,

(7) the internal control management process regarding: process compliance with accepted rules, procedures, supervision requirements and legal regulations, the credibility and reliability of documents arising in the process, the regularity of resource use and means and the timely implementation of the process,

(8) the internal audit management process regarding the adequacy and effectiveness of the assessment of the internal control system in relation to the process of creating and selling insurance products,

(9) the human resources management process in the field of personnel supply,

(10)the administrative management process in the field of material equipment (including information materials and insurance forms),

(11)the IT service management process in the field of IT services.

The process of creating and selling insurance products supports (solid lines in Figure 6):

(1) the process of the management of the insurance company by means of analyses and reports related to the creation and sale of insurance products,

(2) the process of operational planning by means of information on the needs of adjusting operating plans,

(3) the process of the management of process by means of information necessary for the modelling and assessment of the degree of the realization of the goals of the process of creating and selling insurance products,

(4) the process of handling insurance claims within the scope of policy data of concluded insurance contracts,

(5) the process of the management of risk by means of analyses and reports for the purpose of the insurance company's risk management,

(6) the reinsurance management process by means of information on the needs of reinsurance risks related to concluded insurance contracts,

(7) the financial management process by means of information on the amount of contributions related to the concluded insurance contracts and the costs of the process of creating and selling insurance products,

(8) the process of managing insurance technical reserves by means of information on provisions related to concluded insurance contracts,

(9) the process of the investment management of the amount of premiums collected from concluded insurance contracts,

(10)the process of managing sets of insurance statistics by means of information about concluded insurance contracts,

(11)the process of managing legal services and debt collection about the need for debt collection actions related to sold insurance products,

(12)the human resources management process in terms of staffing needs,

(13)the administrative management process in the field of material equipment,

(14)the process of managing IT support by means of information on IT service needs.

\subsection{The Relationship Between the Insurance Claims Handling Process and Other Processes Carried Out in Insurance Companies}

The relationship between the process of handling insurance claims and other processes carried out in insurance companies is presented in Figure 7.

The process of handling insurance claims is supported by information (dotted lines in Figure 7) from:

(1) the strategic planning process for strategic plans in the area of servicing insurance claims,

(2) the operational planning process related to operational plans for servicing insurance claims,

(3) the process of the management of processes in the field of modelling, testing and evaluation of the service process insurance claim service process,

(4) the process of creating and selling insurance products in the field of policy data necessary in the process of handling insurance claims,

(5) the risk management process in the area of the identification, estimation and monitoring of risks related to the handling of insurance claims,

(6) the reinsurance management process of the reinsurance of risks related to serviced claims,

(7) the internal control management process regarding: the process compliance with accepted rules, procedures, supervision requirements and legal regulations, and the credibility and reliability of documents arising in the process, and the regularity of resource and means use and the timely implementation of the process,

(8) the internal audit management process regarding the adequacy and effectiveness of the assessment of he internal control system in relation to the insurance claim handling process,

(9) the human resources management process in the field of personnel supply,

(10)the administrative management process in the field of material equipment,

(11)the IT service management process in the field of IT services. 


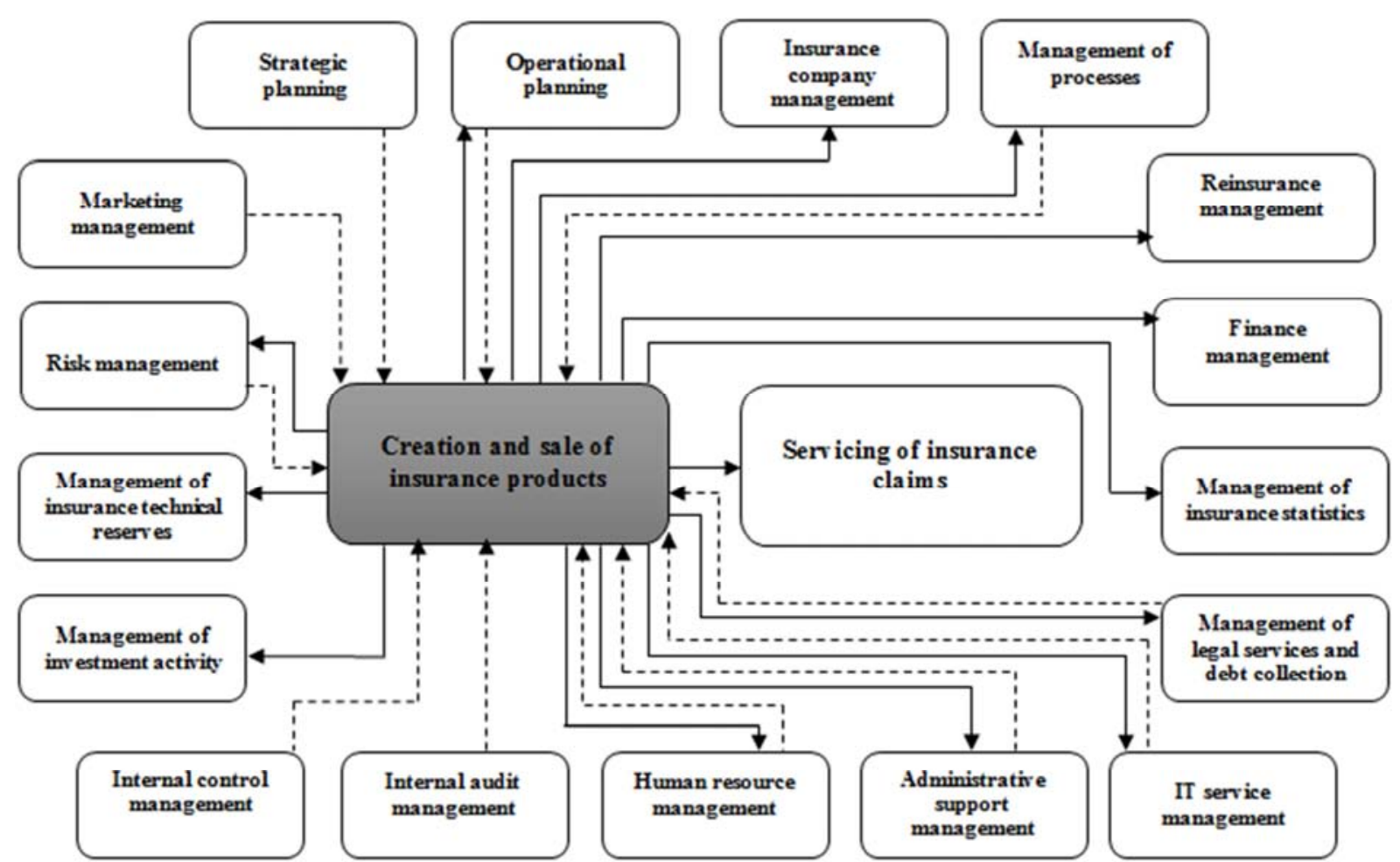

Source: proprietary work

Figure 6. The relationship between the process of the creation and sale of insurance products and other processes carried out in insurance companie.

The process of handling insurance claims supports (continuous lines in Figure 7):

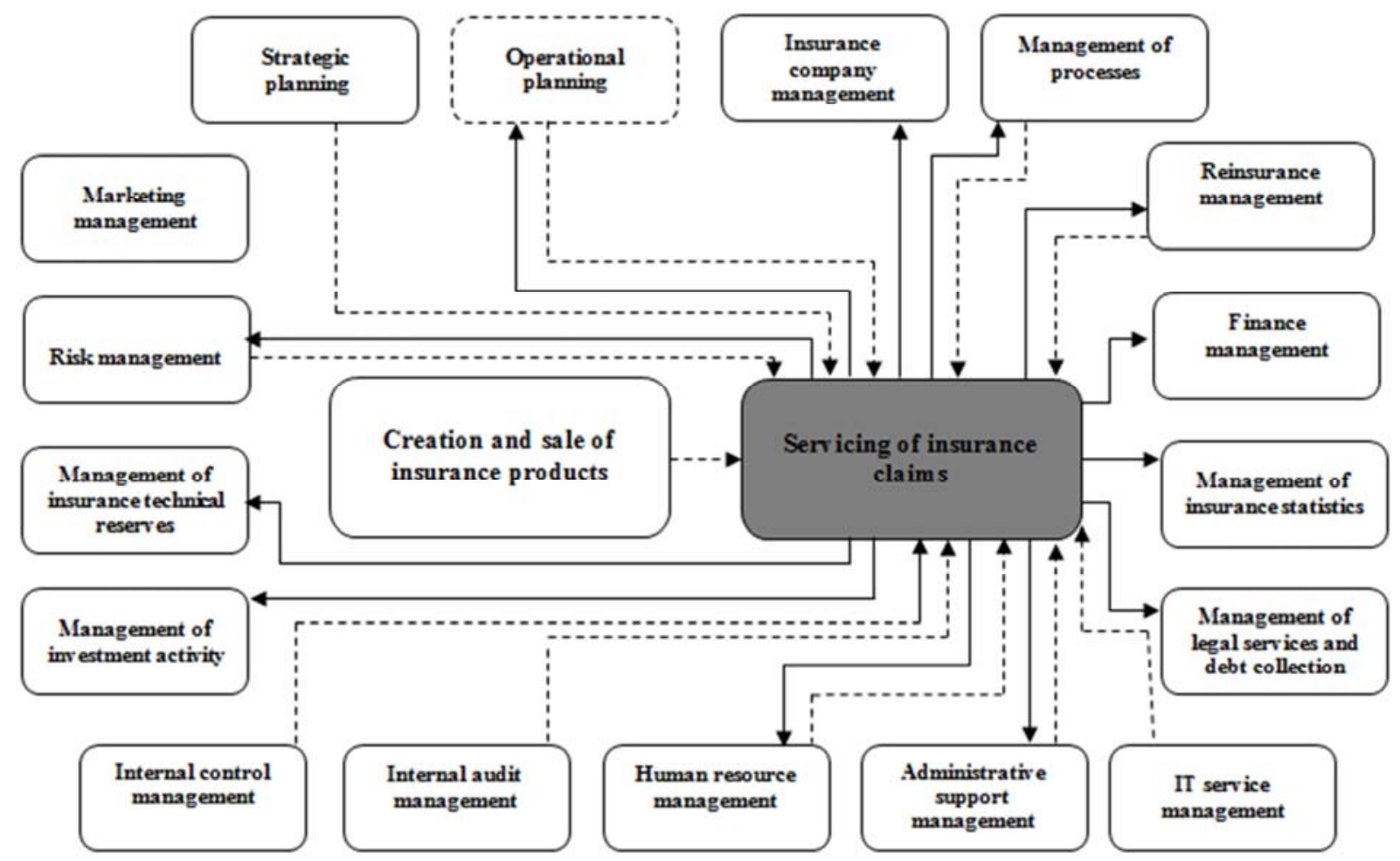

Source: Proprietary work

Figure 7. The relationship between the process of handling insurance claims and other processes carried out in insurance companies.

(1) the process of insurance company management by means of analyses and reports related to the servicing of insurance claims handling,

(2) the process of operational planning by means of 
information on the needs of adjusting operating plans,

(3) the process of risk management by means of analyses and reports concerning the insurance company's risk,

(4) the financial management process on the damages awarded and their payment and on the implementation costs of the insurance claims handling process,

(5) the process of managing insurance technical reserve information on compensation payments reflected in the level of insurance technical reserves,

(6) the process of managing investment activity regarding compensation payments, which may involve with the need to cash in certain financial assets,

(7) the process of managing sets of insurance statistics in terms of damages and recourses and recoveries,

(8) the process of managing legal services and debt collection by means of information on

(9) disputes with clients in terms of the amount of compensation awarded and, if necessary, the settlement of these disputes in court,

(10) the human resources management process in terms of staffing needs,

(11) the administrative support management process in the field of material equipment,

(12) the process of managing IT support by means of information on IT service needs

\section{Conclusions}

The concepts presented in this article may become the basis for discussions by both theoreticians and practitioners dealing with the issues of process management in insurance companies. The presented concept of the process architecture of insurance activity as well as the structure of the basic processes, although they seem to be comprehensive and do take into account the current legal regulations the changing legal and institutional environment, nevertheless, will force upon them change and supplementation. At the level of specific applications, these collections should be adapted to the specific conditions of their implementation.

Previous experience related to the implementation of the management of processes in Polish property insurance companies indicates that these entities have obtained significant benefits in this respect. Implementation of process management enabled the simplification of processes in $50.00 \%$ of insurance companies, the increase in the effectiveness of the functioning of $38.90 \%$ of insurance companies, a faster response to customer needs in $50.00 \%$ of insurance companies and a reduction of the costs of processes in $33.40 \%$ of insurance companies. The implementation of the management of processes resulted in improved cooperation with internal and external clients in $33.40 \%$ of surveyed insurance companies, an increased flexibility of the insurance company in $22.20 \%$ of cases and an increase in work productivity in $22.20 \%$ [2].
Further research in the field of process management in insurance companies will focus on the issues of:

(1) the structure of management and auxiliary processes,

(2) the relationship between management and support processes with other processes implemented in insurance companies,

(3) measures to assess the implementation of individual processes,

(4) the identification of risks related to the implementation of individual processes,

(5) the conditions for the implementation of processes in insurance companies, and

(6) the monitoring and controlling of the implementation of processes.

In the course of further work, it should be borne in mind that the implementation of process management faces a number of difficulties in insurance companies. Research conducted in this field in Polish insurance companies indicates that the biggest barriers to the implementation of process management are: difficulties in the understanding and application of process management $(66.70 \%)$, difficulties in changing employee attitudes $(50.00 \%)$ and employee resistance to constant changes $(61.10 \%)$. In addition, $44.40 \%$ of respondents pointed to problems related to IT systems supporting the management of processes that insurers have at their disposal. A small percentage of the respondents $(11.10 \%)$ indicate the lack of expected effects in the form of the expected increase in the efficiency of processes, while $27.80 \%$ of the respondents indicated problems resulting from the new way of functioning of the insurance company [2].

\section{References}

[1] Trocki M. (2014), Project organization. PWE, Warsaw.

[2] Kruk M. (2018), Cost management in insurance companies from a procedural point of view. Faculty of Management, Warsaw University of Technology.

[3] Hallerbach A., Bauer T., Reichert M. (2008), Managing process variants in the proces life cycle. Proceedings of the Tenth International Conference on Enterprise Information Systems (ICEIS), Barcelona, T. 2.

[4] Dumas M., La Rosa M., Mendling J., Reijers H. (2013), Fundamentals of Business Process Management. Springer, Berlin.

[5] Verma N. (2009), Business Process Management: Profiting from Process. Global India, New Delhi.

[6] Houy C., Fettke P., Loos P. (2010), Empirical research in Business Process Mmanagement. Analysis of an emerging field of research. Business Process Management Journal Vol. 16, No. 4.

[7] Rummler G. A., Brache A. P. (2000), Raising the effectiveness of an organization. PWE, Warsaw.

[8] Gąsiorkiewicz L. (2014), The decomposition process of insurance operations. Foundations of Management, Vol. 6, No. 1. 
[9] Burlton R. (2019), Essentials of Business Architecture: The Business Architecture Concept Model: Strategic Context Phase. https://www.bptrends.com/essentials-of-businessarchitecture-the-business-architecture-concept-model- strategic-context-phase/.

[10] Fleaca E., Fleaca B. (2016), The Business Process Management Map. An Effective Means for Mmanaging the Enterprise Value Chain. Procedia Technology. No. 22. 